\title{
NÍVEIS DE IRRIGAÇÃO NA FORMAÇÃO DE MUDAS DE EUCALIPTO COM UTILIŻAÇÃO DE RESÍDUO SÓLIDO ORGÂNICO URBANO
}

\author{
NOBILE, Fabio Olivieri de ${ }^{1}$ \\ GALBIATTI, João Antonio ${ }^{2}$ \\ MURAISHI, Reginaldo Itiro $^{3}$
}

Recebido em: 2010-02-15

Aprovado em: 2011-10-26

ISSUE DOI: $10.3738 / 1982.2278 .559$

\begin{abstract}
RESUMO: A crescente produção de resíduos gerados pela população humana, especialmente de Resíduo Sólido Orgânico Urbano (R.S.O.U.), requer conhecimento científico que possibilite a sustentabilidade ambiental do planeta. Esta pesquisa teve o objetivo de estudar o efeito da irrigação efetuada por meio da determinação diária da evapotranspiração pelo método do tanque Classe A, multiplicado pelo coeficiente de cultura, associada ao uso de R.S.O.U. para a formação de mudas de eucalipto. A pesquisa foi desenvolvida na Universidade Estadual Paulista (UNESP), Câmpus de Jaboticabal - SP, adotando como delineamento estatístico o esquema fatorial inteiramente casualizado. Foram utilizados 11 substratos: dois tipos de solos - um Latossolo Vermelho eutrófico e um Latossolo Vermelho distrófico, com e sem adubação química; seis misturas de solo e R.S.O.U., e um só de R.S.O.U. Foram utilizados tubetes para a semeadura direta de eucalipto, variedade Citriodora Hooker, e quatro níveis de irrigação $(50 ; 75 ; 100$ e $130 \%)$ da determinação diária. Os dados coletados e analisados estatisticamente demonstram que, em alguns casos, a irrigação associada à utilização de R.S.O.U. possibilitou melhor formação de mudas de eucalipto.
\end{abstract}

Palavras-chave: Água. Irrigação. Material orgânico. Muda. Substrato.

SUMMARY: The increasing production of residues produced by the human population, especially the Urban Organic Solid Residue (U.O.S.R.), has been requiring scientific knowledge that enables the planet environmental maintenance. This research aimed to study the effect of the irrigation that is accomplished through the daily determination of the evapotranspiration by the method of the A rank tank, multiplied by the culture coefficient, associated with the use of U.O.S.R. for the formation of eucalyptus seedlings. The research was developed at the São Paulo State University (UNESP), Jaboticabal - SP, Brazil, adopting as statistic design the entirely casualized factorial scheme. Eleven substrates were used: two types of soils, an eutrophic red latosol and a dystrophic red latosol, with and without chemical fertilization, six mixtures of soil and U.O.S.R., and only one of U.O.S.R.. It was used specific containers for the direct eucalyptus sowing from the variety Citriodora Hooker. Four levels of irrigation were used and 50; 75; 100 and $130 \%$ of the daily determination. The data collected and analyzed statistically show that in some cases the irrigation when associated with the use of U.O.S.R., made it possible for a better formation of eucalyptus seedlings.

Keywords: Water. Irrigation. Organic material. Seedling. Substrate.

\footnotetext{
${ }^{1}$ Prof. Dr. - Solos, Adubos e Adubação- UNIFEB - Centro Universitário da Fundação Educacional de Barretos Av. Professor Roberto Frade Monte no 389, Aeroporto 14783-226 - Barretos - SP - E-mail: fonobile@ feb.br

${ }^{2}$ Professor Titular - Departamento de Engenharia Rural - Faculdade de Ciências Agrárias e Veterinárias UNESP - Jaboticabal, Rodovia Paulo Donato Castellane, km 5, CEP 14.884-900, Jaboticabal, SP. E mail: galbi@fcav.unesp.br

${ }^{3}$ Professor Mestre, - Centro Universitário da Fundação Educacional de Barretos - UNIFEB, Departamento de Agrárias, Av. Professor Roberto Frade Monte n 389 , Aeroporto, Barretos, SP, CEP 14.783-226. Bolsista CNPq. E-mail:fonobile@feb.br
} 


\section{INTRODUÇÃO}

A população mundial passou de 300 milhões de habitantes no ano de 1350, para 900 milhões em 1.800, 5 bilhões em 1980, 6,6 bilhões em 2007, estimando-se que atingirá 9,2 bilhões em 2050 (IBGE, 2010).

O Brasil é, hoje, o segundo país mais populoso do continente americano e de todo o hemisfério ocidental, superado apenas pelos Estados Unidos da América do Norte. Em 1970, $56 \%$ da população brasileira era urbana, hoje está em $75 \%$, chegando a 95\% onde, de cada três moradores, um vive em favela com precário sistema de saneamento e com deposição de lixo a céu aberto (IBGE, 2010). É necessário, então, planejar os destinos dos resíduos urbanos, reaproveitando-os segundo postulado de Lavoisier, em que "na natureza nada se perde, nada se cria, tudo se transforma".

Considerando a carência de entendimento mais amplo do ciclo de vida dos produtos utilizados pelo homem, é necessário que na extremidade final ocorra a sua incorporação ao ciclo de vida no planeta.

Problemas ambientais seriam reduzidos caso fosse possível utilizar o R.S.O.U. (resíduo sólido orgânico urbano) na agricultura, ocorrendo economia e melhoria da qualidade de vida. Os atributos físicos e químicos do solo, como a agregação das partículas, a porosidade, a retenção de água, a condutividade hidráulica, a capacidade de campo e a fertilidade, são favorecidos pelo uso de matéria orgânica. Esses fatores, importantes para a melhoria das condições dos solos agricultáveis, podem tornar os solos pobres de baixa sustentabilidade produtiva, economicamente viáveis (KIEHL, 1985; FERNANDEZ et al., 1987; RUIZ; TEIXEIRA, 1991).

A aplicação agronômica do composto de lixo urbano, quando obtido de modo adequado, é viável devido a sua riqueza em matéria orgânica e nutriente, à ausência de microrganismos patogênicos (XIN et al., 1992; MELO et al., 1997; CRAVO et al., 1998) e às melhorias das condições de cultivo do solo (aumento do teor de matéria orgânica, elevação do $\mathrm{pH}$, redução da acidez potencial e aumento da disponibilidade de fósforo, de potássio, de cálcio e de magnésio), da nutrição e da produção dos vegetais (KIEHL, 1985; LIMA et al., 1999; OLIVEIRA, 2000; ABREU JÚNIOR et al., 2000).

Trabalhando com R.S.O.U., Galbiatti e Lui (2007) concluíram que doses de até $20 \%$ na mistura em solos destinados à produção de mudas de eucalipto não causam efeitos negativos na sobrevivência das plantas, e que existe relação direta entre adições de R.S.O.U., crescimento e número de folhas das plantas. 
Com a irrigação, torna-se possível a produção agrícola em locais antes impossíveis pela falta de chuvas. Quando feita sem critério, entretanto, causa o desperdício de grande quantidade de água.

Para a produção de mudas, há necessidade de se tomar alguns cuidados especiais, entre os quais a quantidade de água fornecida durante o processo de produção, pois, segundo Marquelli e Silva (1993), a disponibilidade de água para a planta, na quantidade correta e no momento oportuno, é decisiva para o sucesso da cultura. Para isso, é importante que se estudem os métodos de estimativas de evapotranspiração. Um dos métodos mais utilizados para a estimativa da evapotranspiração de referência é o método do tanque Classe A, no qual se mede o efeito integrado da radiação solar, vento, temperatura e umidade relativa sobre a evaporação de uma superfície livre de água, onde a planta responde às mesmas variáveis climáticas (KLAR, 1991).

Galbiatti et al. (2004), observaram que é importante conhecer o efeito da deficiência hídrica nos estádios de desenvolvimento das plantas. Na planta, tanto o crescimento quanto o desenvolvimento e a translocação de fotoassimilados encontram-se ligados à disponibilidade hídrica do solo.

Galbiatti; Lui (2007) concluíram que, para níveis de irrigação, misturas de R.S.O.U. em doses de $20 \%$ a $80 \%$ não diferiram estatisticamente para a maior parte dos tratamentos. A sobrevivência, o estabelecimento, a frequência dos tratos culturais e o crescimento inicial das florestas são avaliações necessárias para o sucesso do empreendimento florestal, o que está diretamente relacionado com a qualidade das mudas por ocasião do plantio.

Considerando os problemas advindos da geração de resíduos orgânicos urbanos, o presente trabalho teve por objetivo estudar o efeito da utilização de R.S.O.U. e de irrigação no desenvolvimento de mudas de eucalipto e oferecer subsídios para o aproveitamento dessa parte de matéria orgânica na agricultura.

\section{MATERIAL E MÉTODOS}

O experimento foi conduzido a campo, na Área Demonstrativa e Experimental de Irrigação, do Departamento de Engenharia Rural, da UNESP, Jaboticabal - SP, localizada nas coordenadas $21^{\circ} 15^{\prime} 22^{\prime \prime}$ latitude sul e $48^{\circ} 18^{\prime} 58^{\prime \prime}$ longitude oeste, à altitude média de $575 \mathrm{~m}$ (UNESP, 2009).

A classificação climática para a região, segundo Köeppen, é Cwa: subtropical, com verão úmido e inverno relativamente seco. A temperatura média anual é de aproximadamente 
$22{ }^{\circ} \mathrm{C}$, sendo que, nos meses de junho e julho, se aproxima de $12,5^{\circ} \mathrm{C}$, e de dezembro a fevereiro se aproxima de $30,6^{\circ} \mathrm{C}$. A umidade relativa média do ar é de $70 \%$, podendo atingir $58,2 \%$ nos meses mais secos. A precipitação pluviométrica média anual é $1.400 \mathrm{~mm}$, sendo que $80 \%$ das chuvas ocorrem de outubro a março (UNESP, 2009).

O delineamento experimental utilizado foi o inteiramente casualizado, em esquema fatorial $(11 \times 4 \times 5)$, com três repetições. Foi utilizada irrigação, com base no método do tanque Classe A (considerando Kp igual 0,75 e Kc igual 1,1), e os fatores consistiram de 11 substratos (Tabela 1), quatro níveis de irrigação (50; 75; 100 e 130\% da lâmina calculada com base nos métodos de estimativa da ET) e cinco épocas de avaliação (15; 29; 41; 53 e 79 dias da semeadura). Cada parcela continha 32 tubetes de plástico, em forma de cone, medindo 125 $\mathrm{mm}$ de altura e $27 \mathrm{~mm}$ de diâmetro na parte superior, com capacidade individual de aproximadamente $74 \mathrm{~cm}^{3}$, perfurados na parte inferior e apoiados em bandejas plásticas.

O R.S.O.U. foi obtido a partir da coleta aleatória do resíduo sólido urbano (R.S.U.) na cidade de Jaboticabal - SP. As múltiplas coletas foram homogeneizadas e selecionadas, resultando nas frações inorgânica e orgânica. A fração orgânica (restos de alimentos e cascas de frutas) foi colocada em bandejas e levada à estufa com circulação de ar forçado, à temperatura de $70{ }^{\circ} \mathrm{C}$, até adquirir massa constante. Após a secagem, o material foi triturado em triturador de grãos modelo DPM-4 e passado em peneira de furo redondo de diâmetro de 2 mm, denominando-se de R.S.O.U. Não foi feita a compostagem para verificar os efeitos sem a realização desse processo, ganhando tempo e diminuindo os custos.

Os substratos foram submetidos a análises granulométrica e química, realizadas nos laboratórios do Departamento de Solos e Adubos da UNESP - Jaboticabal. As análises granulométricas foram realizadas por meio do método da pipeta, utilizando-se de $\mathrm{NaOH} 0,1$ mol L $\mathrm{L}^{-1}$ como dispersante, tempo de repouso de 24 horas e agitação lenta, sendo as frações determinadas segundo DAY (1965).

As análises químicas referentes às determinações de acidez trocável $\left(\mathrm{Al}^{3+}\right)$, de macronutrientes (cálcio, magnésio, potássio trocáveis e fósforo disponível) e de micronutrientes $(\mathrm{B}, \mathrm{Cu}, \mathrm{Fe}, \mathrm{Mn}$ e $\mathrm{Zn}$ foram realizadas utilizando-se dos métodos descritos por RAIJ et al. (1987)). O pH foi determinado potenciometricamente, utilizando a relação solo: $\mathrm{CaCl}_{2}$ 0,01 Mol L-1, 1:2,5. Para a determinação do carbono orgânico, seguiu-se a metodologia EMBRAPA (1979). Os resultados da análise granulométrica dos solos e do R.S.O.U. encontram-se na Tabela 2, e os resultados das características químicas dos solos e do R.S.O.U. na Tabela 3.

A semeadura foi feita em tubetes, utilizando-se de sementes de eucalipto, variedade Citriodora Hooker, apoiados em bandejas de 32 unidades, preenchidos manualmente, 
conforme os tratamentos. Inicialmente, as bandejas contendo os tubetes foram emergidas em água até o total encharcamento dos substratos. A seguir, foram retiradas, permitindo a percolação total da água, caracterizando, nesse momento, a capacidade máxima de retenção de água, quando foram semeadas quatro sementes por tubete e cobertas com $2 \mathrm{~mm}$ de solo peneirado. Os tratamentos foram cobertos com sacos de aniagem, sendo retirados assim que as plântulas emergiram. $\mathrm{O}$ desbaste foi efetuado 15 dias após a semeadura, deixando uma muda por tubete.

Tabela 1. Composição dos substratos.

\begin{tabular}{cc}
\hline Substratos & Composição \\
\hline S1 2 & Solo A sem adubação \\
S3 & Solo B sem adubação \\
S4 & Solo A com adubação \\
S5 & Solo B com adubação \\
S6 & Mistura de $80 \%$ de solo A e $20 \%$ de R.S.O.U. \\
S7 & Mistura de $80 \%$ de solo B e $20 \%$ de R.S.O.U. \\
S8 & Mistura de $60 \%$ de solo A e $40 \%$ de R.S.O.U. \\
S9 & Mistura de $60 \%$ de solo B e $40 \%$ de R.S.O.U. \\
S10 & Mistura de $20 \%$ de solo A e $80 \%$ de R.S.O.U. \\
S11 & Mistura de $20 \%$ de solo B e $80 \%$ de R.S.O.U. \\
\end{tabular}

Solo A: Latossolo Vermelho eutrófico, típico textura argilosa, A moderado, caulinítico hipoférrico. Solo B: Latossolo Vermelho distrófico, típico textura arenosa, A moderado, caulinítico hipoférrico (EMBRAPA, 1999), ambos obtidos na profundidade de 0 a $30 \mathrm{~cm}$. Mistura em volume.

Tabela 2. Análise granulométrica dos solos e do R.S.O.U. empregados no experimento.

\begin{tabular}{cccc}
\hline Classe & $\begin{array}{c}\text { Argila } \\
\mathrm{g} \mathrm{kg}^{-1}\end{array}$ & $\begin{array}{c}\text { Silte } \\
\mathrm{g} \mathrm{kg}^{-1}\end{array}$ & $\begin{array}{c}\text { Areia } \\
\mathrm{g} \mathrm{kg}^{-1}\end{array}$ \\
\hline Solo A & 530 & 230 & 340 \\
Solo B & 250 & 70 & 680 \\
R.S.O.U. & 130 & 410 & 460
\end{tabular}

Tabela 3. Características químicas dos solos e do R.S.O.U. empregados no experimento.

\begin{tabular}{|c|c|c|c|c|c|c|c|c|c|c|c|c|c|c|}
\hline Solos & $\begin{array}{l}\mathrm{pH} \\
\mathrm{em}\end{array}$ & $\begin{array}{l}\text { M.O. } \\
\mathrm{g} \mathrm{dm}^{-3}\end{array}$ & 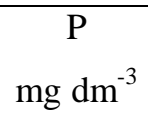 & $\begin{array}{l}\mathrm{K} \\
----\end{array}$ & $\mathrm{Ca}$ & $\begin{array}{r}\mathrm{Mg} \\
\mathrm{imol}\end{array}$ & $\begin{array}{l}\mathrm{H}+\mathrm{Al} \\
\mathrm{n}^{-3}\end{array}$ & SB & $\mathrm{T}$ & B & $\begin{array}{c}\mathrm{Cu} \\
\mathrm{mg} \mathrm{dr}\end{array}$ & $\mathrm{Fe}$ & $\mathrm{Mn}$ & $\mathrm{Zn}$ \\
\hline Solo A & 6,0 & 21 & 43 & 1,5 & 34 & 30 & 20 & 65,5 & 85,5 & 0,13 & 1,4 & 6,0 & 7,4 & 0,6 \\
\hline Solo B & 4,4 & 15 & 15 & 1,6 & 12 & 5 & 38 & 18,6 & 56,6 & 0,13 & 0,4 & 14 & 5,5 & 0,3 \\
\hline R.S.O.U & 6,0 & 193 & 310 & 45 & 250 & 50 & 22 & 345 & 367 & 8,86 & 0,9 & 9,0 & 7,9 & 4,1 \\
\hline
\end{tabular}


Os tratamentos dos solos com adubação (S3 e S4) consistiram da adubação foliar $\left(\mathrm{NP}_{2} \mathrm{O}_{5} \mathrm{~K}_{2} \mathrm{O}+\right.$ micronutrientes), na formulação 16-32-16, aplicando-se $25 \mathrm{~mL}$ por planta cada vez, via foliar, aos 35 e aos 42 dias após a semeadura, nas dosagens respectivas de $1 \%$ e $4 \%$ de adubo foliar. Todos os tratamentos receberam aos 56 dias, junto à rega, 0,05 g de uréia, e aos 63 dias, uma rega com $1 \%$ de uréia e $1 \%$ de $\mathrm{KCl}$.

Após a semeadura, os substratos foram colocados em condições de máxima retenção de água e, durante 30 dias, receberam duas irrigações diárias, conforme rotina de um viveiro de mudas. Após esse período, os substratos foram colocados novamente em condições de máxima retenção de água e iniciada a irrigação por aspersão, com regadores manuais, baseada no método de controle.

A área do experimento foi mantida isenta de plantas daninhas por meio de arranquio manual nos tubetes e de capinas manuais nas imediações das bandejas-suporte dos tubetes. Nenhum defensivo químico foi utilizado para o combate das plantas daninhas, pragas e doenças.

Para a determinação do número de tubetes com plantas vivas, foram efetuadas contagens aos 15; 29; 41; 53 e 79 dias após a semeadura. Nessas mesmas datas, em dez plantas por tratamento, em todas as parcelas, foram determinados a altura média, considerando-se a distância do colo da planta à extremidade da folha que atingiu a maior distância da base, e o número médio de folhas por planta.

As análises estatísticas foram realizadas pelos procedimentos do STatistical Analysis System (SAS INSTITUTE, 1999), sendo as comparações de médias realizadas por meio do teste de Tukey, a $5 \%$ de probabilidade.

\section{RESULTADOS E DISCUSSÃO}

Comparando o número médio de tubetes com plantas vivas em diferentes épocas após a semeadura (Tabelas 4 e 5), verificou-se que, aos 15 e 29 dias, os substratos estudados não apresentaram diferenças significativas. Aos 41 dias, somente o substrato S11 apresentou diferença. Aos 53 e 79 dias, somente os substratos S9, S10 e S11 diferiram estatisticamente dos demais. As diferenças, segundo Galbiatti (1992), podem estar associadas à biodegradação do material orgânico.

Para as variáveis altura média de plantas (Figura 1) e número médio de folhas por planta (Figura 2), avaliadas aos 79 dias após a semeadura, a adição crescente de R.S.O.U. nos substratos (de 20 a 100\%) apresentou efeito negativo proporcional às quantidades utilizadas, entretanto o crescimento foi homogêneo em todos os substratos, nas diferentes idades. 
Tabela 4. Valores de F e Coeficientes de Variação (CV) obtidos na Análise de Variância para número de tubetes com plantas vivas e altura de plantas.

\begin{tabular}{ccc}
\hline Valor F & Tubetes com Plantas Vivas & Altura de Plantas \\
\hline Substrato (SB) & $47,92^{* * *}$ & $287,94^{* * *}$ \\
Idade (ID) & $210,36^{* *}$ & $1.287,98^{* *}$ \\
Nível de Irrigação (NI) & $13,90^{* *}$ & $4,33^{* *}$ \\
Interação SB x ID & $15,83^{* *}$ & $15,27^{* *}$ \\
Interação SB x NI & $2,75^{* *}$ & $0,96^{\mathrm{NS}}$ \\
Interação ID x NI & $2,13^{*}$ & $3,23^{* *}$ \\
Interação SB x ID x NI & $0,21^{\mathrm{NS}}$ & $0,43^{\mathrm{NS}}$ \\
\hline C.V. \% & 9,11 & 12,23 \\
\hline
\end{tabular}

Tabela 5. Número médio de tubetes com plantas vivas, avaliados aos 15, 29, 41, 53 e 79 dias após a semeadura.

\begin{tabular}{cccccc}
\hline \multirow{2}{*}{ Substrato } & \multicolumn{5}{c}{ Avaliações } \\
\cline { 2 - 6 } S1 & $23,04 \mathrm{aA}$ & $23,50 \mathrm{aA}$ & $22,00 \mathrm{aAB}$ & $20,42 \mathrm{aA}$ & $19,17 \mathrm{aA}$ \\
S2 & $25,10 \mathrm{aA}$ & $24,92 \mathrm{aA}$ & $23,13 \mathrm{aAB}$ & $22,21 \mathrm{aA}$ & $21,54 \mathrm{aA}$ \\
S3 & $22,38 \mathrm{aA}$ & $22,25 \mathrm{aA}$ & $20,42 \mathrm{aAB}$ & $18,17 \mathrm{aAB}$ & $17,25 \mathrm{aA}$ \\
S4 & $26,46 \mathrm{aA}$ & $26,13 \mathrm{aA}$ & $25,42 \mathrm{aA}$ & $23,50 \mathrm{aA}$ & $22,54 \mathrm{aA}$ \\
S5 & $25,21 \mathrm{aA}$ & $26,08 \mathrm{aA}$ & $24,92 \mathrm{aAB}$ & $23,38 \mathrm{aA}$ & $22,42 \mathrm{aA}$ \\
S6 & $22,54 \mathrm{aA}$ & $23,04 \mathrm{aA}$ & $21,46 \mathrm{aAB}$ & $19,96 \mathrm{aA}$ & $18,71 \mathrm{aA}$ \\
S7 & $23,67 \mathrm{aA}$ & $23,96 \mathrm{aA}$ & $22,63 \mathrm{aAB}$ & $20,92 \mathrm{aA}$ & $19,21 \mathrm{aA}$ \\
S8 & $23,88 \mathrm{aA}$ & $24,42 \mathrm{aA}$ & $22,96 \mathrm{abAB}$ & $19,88 \mathrm{abA}$ & $17,92 \mathrm{bA}$ \\
S9 & $25,71 \mathrm{aA}$ & $27,17 \mathrm{aA}$ & $24,12 \mathrm{aAB}$ & $13,54 \mathrm{bB}$ & $10,71 \mathrm{bB}$ \\
S10 & $25,33 \mathrm{aA}$ & $26,38 \mathrm{aA}$ & $23,79 \mathrm{aAB}$ & $13,58 \mathrm{bB}$ & $3,50 \mathrm{cB}$ \\
S11 & $24,33 \mathrm{aA}$ & $25,71 \mathrm{aA}$ & $19,21 \mathrm{bB}$ & $3,50 \mathrm{cB}$ & $1,92 \mathrm{cC}$ \\
\hline C.V.\% & 8,11 & 10,2 & 13,4 & 11,72 & 15,6
\end{tabular}

Médias seguidas de mesma letra minúscula (na linha) e maiúscula (na coluna) não diferem entre si, pelo Teste de Tukey, a $5 \%$ de probabilidade. C.V. - coeficiente de variação.

Deve-se, portanto, atentar-se para o fato de que aplicações sucessivas e em elevadas doses do composto de lixo, sem o devido monitoramento, podem causar efeitos negativos ao solo e às plantas. A salinização, avaliada pela condutividade elétrica (GARCIA et al., 1992; ABREU JÚNIOR et al., 2000), o acúmulo de metais (CRAVO et al., 1998), a lixiviação de nitratos (OLIVEIRA, 2000), a dispersão dos colóides e a redução da condutividade hidráulica do solo, decorrentes da substituição do cálcio e do magnésio da interface solução do solosuperfície coloidal pelo sódio e pelo potássio, presentes em altas concentrações no composto 
de lixo (MELO et al., 1997), são os principais aspectos ambientais a serem monitorados para o sucesso dessa prática.

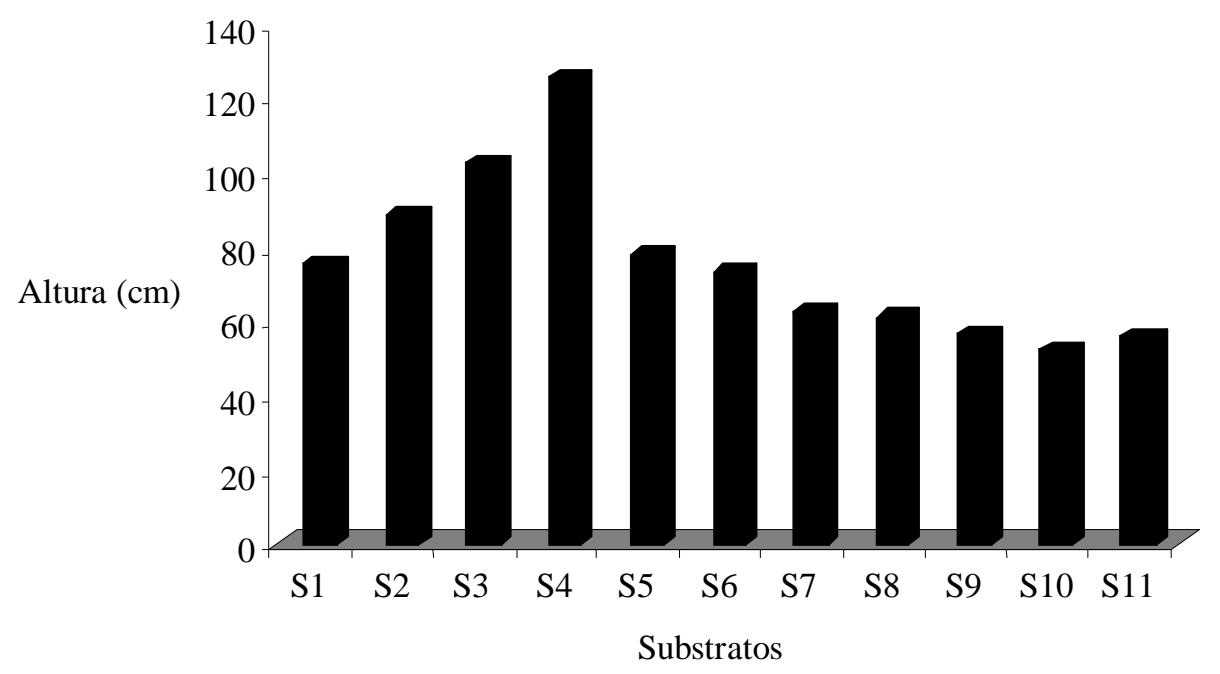

Figura 1. Altura média de plantas (cm), avaliadas aos 79 dias após a semeadura.

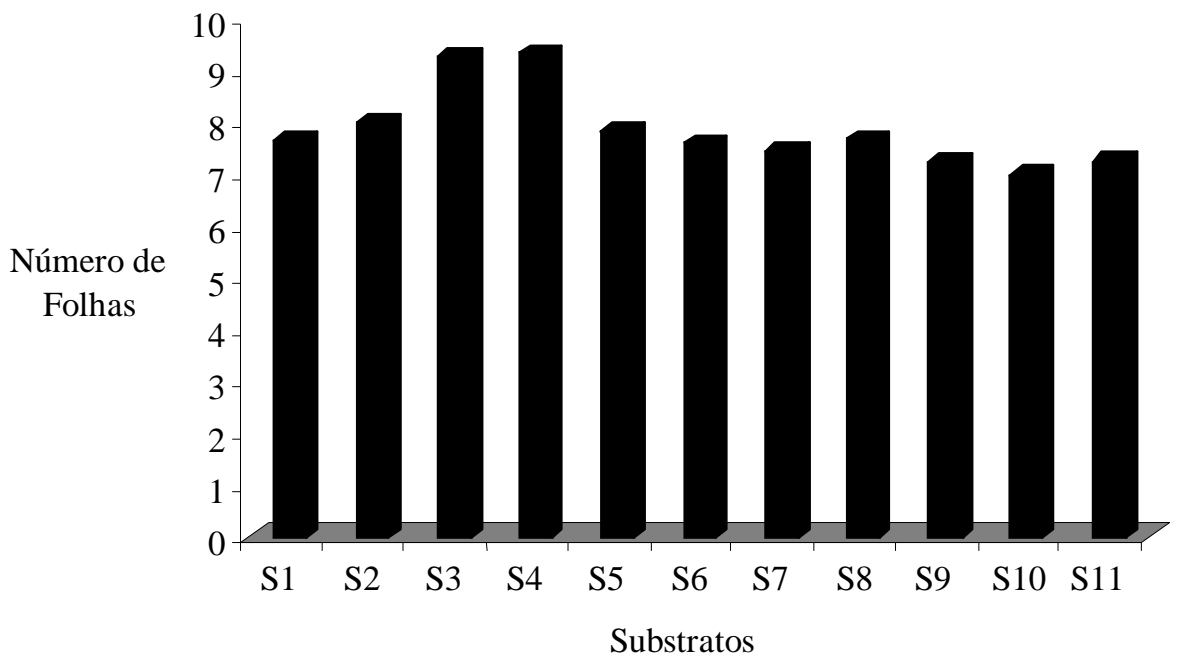

Figura 2. Número médio de folhas por planta, avaliadas aos 79 dias após a semeadura.

Analisando os valores médios do número de tubetes com plantas vivas, em função da irrigação (TCA) (Tabela 6), verifica-se que o S5 foi o que teve maior número médio de tubetes com plantas vivas, não apresentando diferença estatística com S2 e S4. 
Tabela 6. Valores médios do número de tubetes com plantas vivas.

\begin{tabular}{ll}
\hline \multirow{2}{*}{ Substrato } & \multicolumn{1}{c}{ Irrigação } \\
\cline { 2 - 2 } S1 & TCA \\
\hline S2 & $17,33 \mathrm{CD}$ \\
S3 & $18,28 \mathrm{ABC}$ \\
S4 & $14,00 \mathrm{D}$ \\
S5 & $21,42 \mathrm{AB}$ \\
S6 & $21,68 \mathrm{~A}$ \\
S7 & $15,80 \mathrm{CD}$ \\
S8 & $16,25 \mathrm{CD}$ \\
S9 & $16,15 \mathrm{CD}$ \\
S10 & $17,78 \mathrm{BC}$ \\
S11 & $15,87 \mathrm{CD}$ \\
\hline
\end{tabular}

Médias seguidas de mesma letra não diferem entre si, pelo Teste de Tukey, a 5\% de probabilidade.

À medida que se aumentou a percentagem de R.S.O.U., foi menor o desenvolvimento em altura das plantas e no número médio de folhas por planta. $\mathrm{O}$ efeito prejudicial ao desenvolvimento das plantas pode ser pelo fato de o R.S.O.U. ter sido utilizado logo após a secagem em estufa. De acordo com Kiehl (1985), o composto orgânico utilizado como fertilizante resulta de processo de decomposição bioquímica de materiais orgânicos, transformado em produto mais estável.

Costa et al. (2001) obtiveram aumento linear na produção de matéria fresca da hortaliça, aumento significativo nos teores de zinco da parte aérea e nenhum efeito nos de cobre, níquel e chumbo com a aplicação de composto de lixo urbano.

Ao comparar o número de tubetes com plantas vivas nos diferentes substratos e níveis de irrigação (Tabela 7), verifica-se que, no nível de 75\% da evapotranspiração, o substrato S4 apresentou o maior número de tubetes com plantas vivas, embora não diferindo estatisticamente dos substratos S1, S2, S3, S5, S7, S8, S9 e S11.

Verifica-se, também, que, no nível de 50\% da evapotranspiração, o substrato S11 apresentou o menor número de tubetes com plantas vivas, embora não diferindo estatisticamente dos substratos S3, S6, S9 e S10. 
Tabela 7. Número médio de tubetes com plantas vivas nos substratos, em cada nível de irrigação aos 79 dias.

\begin{tabular}{cllll}
\hline \multirow{2}{*}{ Substrato } & \multicolumn{4}{c}{ Nível de Irrigação } \\
\cline { 2 - 5 } & $50 \%$ & $75 \%$ & \multicolumn{1}{c}{$100 \%$} & $130 \%$ \\
\hline S1 & $22,63 \mathrm{aA}$ & $23,00 \mathrm{aAB}$ & $21,70 \mathrm{aABC}$ & $19,17 \mathrm{aAB}$ \\
S2 & $22,53 \mathrm{aA}$ & $23,18 \mathrm{aAB}$ & $24,20 \mathrm{aAB}$ & $23,60 \mathrm{aA}$ \\
S3 & $18,07 \mathrm{aAB}$ & $21,90 \mathrm{aAB}$ & $20,77 \mathrm{aABC}$ & $19,63 \mathrm{aAB}$ \\
S4 & $20,93 \mathrm{bA}$ & $26,83 \mathrm{aA}$ & $26,23 \mathrm{aA}$ & $25,23 \mathrm{aA}$ \\
S5 & $22,17 \mathrm{bA}$ & $26,03 \mathrm{aAB}$ & $24,47 \mathrm{abAB}$ & $24,93 \mathrm{abA}$ \\
S6 & $20,67 \mathrm{aAB}$ & $20,33 \mathrm{aB}$ & $20,43 \mathrm{aAB}$ & $23,13 \mathrm{aA}$ \\
S7 & $21,30 \mathrm{aA}$ & $21,47 \mathrm{aAB}$ & $22,43 \mathrm{aAB}$ & $23,10 \mathrm{aA}$ \\
S8 & $20,87 \mathrm{aA}$ & $22,05 \mathrm{aAB}$ & $23,13 \mathrm{aAB}$ & $20,73 \mathrm{aAB}$ \\
S9 & $18,73 \mathrm{aAB}$ & $23,00 \mathrm{aAB}$ & $20,37 \mathrm{aAB}$ & $18,97 \mathrm{aAB}$ \\
S10 & $18,97 \mathrm{aAB}$ & $20,30 \mathrm{aB}$ & $19,67 \mathrm{aBC}$ & $19,43 \mathrm{aAB}$ \\
S11 & $14,10 \mathrm{aB}$ & $14,07 \mathrm{aAC}$ & $16,53 \mathrm{aC}$ & $15,03 \mathrm{aB}$
\end{tabular}

Médias seguidas de mesma letra minúscula (na linha) e maiúscula (na coluna) não diferem entre si, pelo Teste de Tukey, a $5 \%$ de probabilidade.

No nível de irrigação $75 \%$ da evapotranspiração, o melhor resultado observado foi no S4, embora diferenciando estatisticamente apenas de S6, S10 e S11. Para o nível de irrigação de $100 \%$ da evapotranspiração, o substrato que melhor se comportou em relação ao número de tubetes com plantas vivas foi o S4, embora tenha apenas diferido estatisticamente do S10. O substrato S11 foi o que apresentou menor número de tubetes com plantas vivas, no nível de irrigação de $130 \%$ da evapotranspiração, embora não diferindo estatisticamente dos substratos S1, S3, S9 e S10. Os substratos de S1 a S10 não apresentaram diferença estatística.

Os resultados mostram que o aumento na quantidade de água aplicada proporcionou maior número de tubetes com plantas vivas, havendo relação direta entre os níveis de água e o número de tubetes com plantas vivas, apesar de, estatisticamente, ter sido significativo apenas no substrato S5. O efeito físico causado pela matéria orgânica no solo é importante para o desenvolvimento dos vegetais; segundo Henin et al. (1976), seu efeito na melhoria da estrutura do solo constitui fator positivo para o desenvolvimento das raízes. Essa melhoria está relacionada, também, com o regime de água, pois melhorando a capacidade de infiltração, acelera o processo dinâmico da água no solo.

Conforme observado na Tabela 8, o número de folhas por planta foi crescente com o aumento da idade das mudas. 
Tabela 8. Número médio de tubetes com plantas vivas e número médio de folhas por plantas em função da época de avaliação (dias após a semeadura).

\begin{tabular}{lcrrrr}
\hline \multirow{2}{*}{ Variável } & \multicolumn{5}{c}{ Idade } \\
\cline { 2 - 6 } & \multicolumn{1}{c}{15} & \multicolumn{1}{c}{49} & \multicolumn{1}{c}{41} & \multicolumn{1}{c}{79} \\
\hline Tubetes c/ plantas vivas & $20,55 \mathrm{a}$ & $20,29 \mathrm{a}$ & $18,10 \mathrm{a}$ & $14,42 \mathrm{a}$ & $12,86 \mathrm{a}$ \\
Folhas por planta & - & $4,58 \mathrm{a}$ & $6,00 \mathrm{a}$ & $7,01 \mathrm{a}$ & $8,18 \mathrm{a}$
\end{tabular}

Médias seguidas da mesma letra na coluna (maiúscula) e na linha (minúscula) não diferem entre si, pelo Teste de Tukey, a $5 \%$ de probabilidade.

De acordo com a Tabela 9, à altura média de plantas, não se constataram diferenças estatísticas significativas entre os níveis de irrigação (Tabela 9).

Tabela 9. Altura média de plantas (mm), analisadas em função da irrigação.

\begin{tabular}{cccccc}
\hline \multirow{2}{*}{ Variável } & TI & \multicolumn{4}{c}{ Níveis de Irrigação (\%ET) } \\
\cline { 3 - 6 } & & 50 & 75 & 100 & 130 \\
\hline Altura de plantas & TCA & $46,17 \mathrm{a}$ & $48,29 \mathrm{a}$ & $46,54 \mathrm{~b}$ & $48,57 \mathrm{a}$ \\
\hline
\end{tabular}

Médias seguidas da mesma letra na coluna (maiúscula) e na linha (minúscula) não diferem entre si, pelo Teste de Tukey, a $5 \%$ de probabilidade.

\section{CONCLUSÃO}

Misturas a partir de $20 \%$ de R.S.O.U. apresentam tendência de diminuir o número de plantas vivas.

Existe relação direta entre adições de R.S.O.U., crescimento e número de folhas das plantas.

Doses de até $20 \%$ de R.S.O.U., sem compostagem, na mistura em solos destinados à produção de mudas de eucalipto, não causam efeitos negativos na sobrevivência das plantas.

No nível de $75 \%$ da evapotranspiração, foi obtido o maior número de tubetes com plantas vivas.

Em todos os níveis de irrigação associados ao substrato com R.S.O.U. puro ocorreram menores números de tubetes com plantas vivas. 


\section{REFERÊNCIAS}

ABREU JÚNIOR, C. H.et al. Condutividade elétrica, reação do solo e acidez potencial em solos adubados com composto lixo. Revista Brasileira de Ciência do Solo, Viçosa, v.24, n.4, p.635-647, 2000.

COSTA, C. A.et al. Teor de metais pesados e produção de alface adubada com composto de lixo urbano. Horticultura Brasileira, Brasília, v.19, n.1, p.10-16, 2001.

CRAVO, M. S.; MURAOKA, T.; GINE-ROSIAS, M. F. G. Caracterização química de compostos de lixo urbano de algumas usinas brasileiras. Revista Brasileira de Ciência do Solo, Viçosa, v.22, p.547-553, 1998.

DAY, P. R. Particle fracionation and particle - size analysis. In: BLACK, C.A. Methods of soil analysis. Madison: American Society of Agronomy, 1965. part 1, cap. 43, p.545-567. (ASA, 9).

EMBRAPA. EMPRESA BRASILEIRA DE PESQUISA AGROPECUÁRIA. Serviço Nacional de Levantamento e Conservação do Solo. Manual de métodos de análise de solo. Rio de Janeiro, 1979. 247 p.

EMBRAPA. EMPRESA BRASILEIRA DE PESQUISA AGROPECUÁRIA. Centro Nacional de Pesquisa de Solos. Sistema Brasileiro de Classificação de Solos. Brasília, 1999. $412 \mathrm{p}$.

FERNANDEZ, J. E.et al. Influencia del aporte continuado de resíduos sólidos urbanos sobre propriedades físicas del suelo. In: CONGRESSO NACIONAL DE QUÍMICA, 7., 1987, Sevilha. Anais... Sevilha, 1987. 1 CD-ROM.

FONSECA, E. P. Padrão de qualidade de mudas de Trema micrantha (L.) Blume Cedrela fissilis Vell. e Aspidosperma polyneuron Müll. Arg. produzidas sob diferentes períodos de sombreamento. 2000. 113 f. Tese (Doutorado em Produção Vegetal) Faculdade de Ciências Agrárias e Veterinárias, Universidade Estadual Paulista, Jaboticabal.

GALBIATTI, J. A. Efeito do uso contínuo de efluente de biodigestos sobre algumas características físicas do solo e o comportamento do milho (Zea Mays L.). 1992. 212 f. Tese (Livre-Docência) - Faculdade de Ciências Agrárias e Veterinárias, Universidade Estadual Paulista, Jaboticabal.

GALBIATTI, J. A.et al. Efeito de diferentes períodos de irrigação no desenvolvimento, produção e qualidade de sementes de milho. Engenharia Agrícola, Jaboticabal, v.24, n. 2, p. 301-308, 2004.

GALBIATTI, J. A.et al. Formação de mudas de eucalipto com utilização de lixo orgânico e níveis de irrigação calculados por dois métodos. Engenharia Agrícola, Jaboticabal, v.27, n.2, p. 326-358, 2007.

GARCIA, C.et al. Phytotoxicity due to the agricultural use of urban wastes. Germination experiments. Journal Science Food Agricultural, New Jersey, v.59, n.3, p.313-19, 1992. 
GOMES, J. M.et al. Efeito de diferentes substratos na produção de mudas de Eucalyptus grandis W. Hill ex Maiden, em "Win-Strip". Revista Árvore, Viçosa, v.15, n.1, p.35-42, 1991.

HENIN, S.; GRAS, R.; MONNIER, G. Os solos agrícolas. Rio de Janeiro: Forense, Universitária, 1976. 327 p.

IBGE. INSTITUTO BRASILEIRO DE GEOGRAFIA E ESTATÍSTICA. Censo

Demográfico 2010: Migração e Deslocamento. Brasília: Ministério de Planejamento, Orçamento e Gestão. Brasília, 2010.

KIEHL, E. J. Fertilizantes orgânicos. São Paulo: Agronômica Ceres, 1985. 492 p.

KLAR, A. E. Irrigação: frequência e quantidade de aplicação. São Paulo: Nobel, 1991. 156 p.

LIMA, J. S.et al. Hortaliças cultivadas com composto orgânico de lixo urbano não apresentam contaminação com metais pesados. Revista Ceres, Viçosa, v.46, p.571-85, nov./dez.1999.

MARQUELLI, W. A.; SILVA, W. L. C. Adequação da época de paralisação das irrigações em tomate industrial no Brasil Central. Horticultura Brasileira, Brasília, v.11, n.2, p.118$121,1993$.

MELO, W. J.et al. Uso de resíduos sólidos urbanos na agricultura e impactos ambientais. In: CONGRESSO BRASILEIRO DE CIÊNCIA DO SOLO, 26., 1997. Rio de Janeiro. Anais... Rio de Janeiro: EMBRAPA/SBCS, 1997. 1 CD-ROM.

OLIVEIRA, F. C. Disposição de lodo de esgoto e composto de lixo urbano num Latossolo Vermelho-Amarelo cultivado com cana-de-açúcar. Piracicaba, 2000. $247 \mathrm{f}$. Tese (Doutorado em Solos e Nutrição de Plantas) - Escola Superior de Agricultura "Luiz de Queiroz", Universidade de São Paulo, Piracicaba.

RAIJ, B.et al. Análise química do solo para fins de fertilidade. Campinas: Fundação Cargill, 1987. 170 p.

RUIZ, H. A.; TEIXEIRA, E. A. Retenção de água em materiais de solos tratados com dois compostos orgânicos. In: CONGRESSO BRASILEIRO DE CIÊNCIA DO SOLO, 23., 1991, Porto Alegre. Anais... Porto Alegre: Sociedade Brasileira de Ciência do Solo, 1991.

UNESP. Universidade Estadual Paulista. Disponível em: <http://www.fcav.unesp.br/estacao. Acesso em: 25 fev. 2009.

XIN, T. H.; TRAINA, S. J.; LOGAN, T. J. Chemical properties of municipal solid waste compost. .Journal of Environmental Quality, Madison, v.21, n.4, p.318-329, 1992. 
